\title{
Throwing Arm Injuries
}

Tony Kochhar* and Harry Batty

Department of Trauma \& Orthopaedics, Queen's Hospital Romford, UK

*Corresponding author: Tony Kochhar, Department of Trauma \& Orthopaedics, Queen's Hospital Romford, Essex, UK, Tel: 0203 301 3750 ; Fax: 01622 620921; Email: tonykochhar@gmail.com

Rec date: Oct 14, 2013, Acc date: Nov 12, 2014, Pub date: Nov 14, 2014

Copyright: (C) 2014 Kochhar T, et al. This is an open-access article distributed under the terms of the Creative Commons Attribution License, which permits unrestricted use, distribution, and reproduction in any medium, provided the original author and source are credited.

\begin{abstract}
Throwing arm injuries are common, especially in overhead or throwing sports. They can lead to loss of performance, periods of time off the court or even surgery. This review article discusses the anatomy and biomechanics of the shoulder, in order to explain how we can avoid these injuries and improve performance.
\end{abstract}

Keywords: Shoulder; Tennis; Throwing arm; Rotator cuff; Labrum; Biceps; Rehabilitation

\section{Introduction}

The extensive range of motion of the shoulder joint allows the athlete to engage in a multitude of sporting activities [1]. This is particularly true of sports which involve overhead throwing. The act of throwing means different things in different sports but essentially the biomechanics are such that it involves the sequential coordination of a range of muscles from the athlete's feet to their fingers, known as the kinetic chain $[2,3]$. Studies on baseball, cricket and tennis players, the so-called overhead throwing athletes, have shown that the repetitive straining of the balance between shoulder mobility and stability can lead to some common throwing arm injuries [4-6]. The aim of this article is to outline the mechanisms behind these injuries and the various ways in which they can be managed.

\section{The Mechanics of the Throwing Shoulder}

In abduction the average shoulder can externally rotate to 90 degrees and rotate through an arc of 180 degrees (i.e. from vertically up down to vertically down).

This arc of movement is controlled by the external and internal rotators.

The problem is that when we throw, the ball is released from the overhead position (i.e. position B). By that point however, the arm must have reached maximal acceleration in order for the ball to be thrown at fast pace. The analogy is that of a catapult - the further back you pull the elastic, the faster the missile flies out when released (the shoulder being the elastic and the ball being the missile). If however, the point of release is actually the furthest back (into ER) the shoulder can normally move, either the ball falls to the ground with no speed imparted, or the shoulder and arm needs to start/be wound back into an abnormal range of movement (Zone A-B).

It is therefore an advantage to overhead throwers who are hypermobile or even just flexible, so that they can increase their range of motion into this zone. In order to throw as fast as possible, this "acceleration" zone should be as long as possible and the athlete will naturally train his technique and his Internal Rotators (IR) to create maximal rapid force in this zone. We are therefore training overhead athletes to move their shoulders in abnormal ranges and at excessive forces.

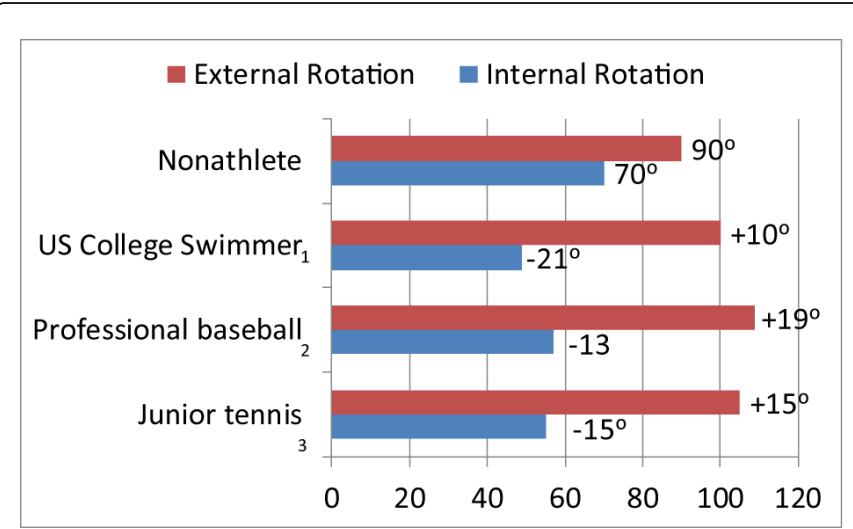

Figure 1: Mechanics of the throwing shoulder.

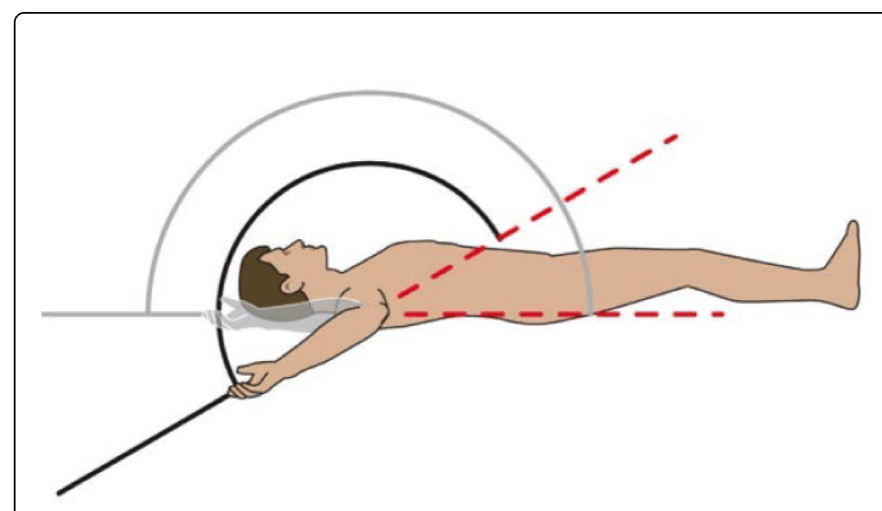

Figure 2: Arc of motion.

In these abnormal zones, tissues can be impinged upon. Internal impingement is a physiological phenomenon in which the undersurface of the rotator cuff contacts the postero-superior aspect of the labrum with the arm in maximal ER and abduction. This can lead to symptoms from repetitive microtrauma leading to failure of the 
Page 2 of 4

undersurface cuff fibres and bicipto-labral complex. This is caused by poor conditioning or over-throwing [7-14].

We can change this arc of motion but it is more difficult to increase the 180 degree range and studies show that people who participate in such sports are able to start the arc further back, but conversely stop further forwards. This leads to the Glenohumeral Internal Rotation Deficit (GIRD) (Figures 1 and 2).

In these abnormal zones, tissues can be impinged upon. Internal impingement is a physiological phenomenon in which the undersurface of the rotator cuff contacts the posterosuperior aspect of the labrum with the arm in maximal ER and abduction. This can lead to symptoms from repetitive microtrauma leading to failure of the under surface cuff fibres and bicipto-labral complex. This is caused by poor conditioning or over-throwing [7-14].

Most of the science comes from baseball and tennis (and some from cricket). These show that from wind up to ball release, it takes about 1.5 seconds to generate angular velocities of up to 7000 degrees/sec to bowl a ball of about $90 \mathrm{mph}$. These forces approach the fatigue strength of many of the soft tissue constraints of the shoulder.

All six phases of throwing take approximately 2 seconds and the acceleration phase 4 is the shortest, lasting approx only 0.05 seconds. However, during this shortest phase, the greatest angular velocities are created and the forces (resulting in the greatest change in rotation) occur. This is the most vulnerable point for the shoulder, and that is why most overhead athletes initially report a "catch" of pain as symptoms first appear. This catch usually only occurs at this point and is therefore ignored. Unfortunately it develops through all phases and then into other activities.

At the point of release, the arm/ball needs to be moving at maximal acceleration. The ball is released, and then the shoulder needs to stop the "deceleration" zone.

At the point of release, the arm is essentially trying to fling itself out of the shoulder joint. These humeral distraction forces (up to approx $950 \mathrm{~N}$; cf compressive forces created by the cuff and deltoid after ball release of up to $1100 \mathrm{~N}$ ) approach the ultimate tensile strength of the shoulder capsule and ligaments stabilizing the shoulder). So if the compressive forces do not cancel out the distraction forces, injuries will occur.

We do not directly have brakes in the body to stop acceleration. In this scenario, the acceleration comes from concentric IR activity and the "brakes" come on by eccentric activation of the External Rotators (ER).

There are only two problems now. The first is whether the "braking distance" is long enough. The second is whether the balance between the concentric IR's and eccentric ER's in this zone are balanced and controlled. Studies have shown that in high-velocity throwers, such as fast bowlers in cricket, if there is imbalance between IR and ER in this phase, these is resultant dynamic excess IR and this leads to narrowing of the subacromial space and resultant dynamic SA impingement [15-28].

\section{Don't Forget the Hyper-Mobility}

Given that we have decided that our optimal high-velocity overhead thrower is tall (long levers to generate greater moments of inertia) and that they train so that their shoulders now move in abnormal range at massive forces, it comes as no surprise that when we also like our athletes to be hypermobile injuries occur. This is of greatest importance during the deceleration phase especially in high-velocity throwing where distraction forces may be highest (Table 1).

\begin{tabular}{|l|l|}
\hline Injury & Pathomechanics \\
\hline SLAP Tear & $\begin{array}{l}\text { GIRD, Internal Impingement, } \\
\text { insufficient braking distance }\end{array}$ \\
\hline Dynamic SA Impingement & Acceleration Deceleration Imbalance \\
\hline PASTA lesion & GIRD, Internal Impingement \\
\hline RC tear & $\begin{array}{l}\text { GIRD, Accel-Decel imbalance, } \\
\text { Hypermobility-distraction, progression } \\
\text { of Dynamic impingment }\end{array}$ \\
\hline Anterior Labral tear/Instability & Hypermobility \\
\hline
\end{tabular}

Table 1: What injuries occur.

\section{Prevention and Treatment}

Fortunately most overhead-throwing sportsmen do not need surgery and symptoms become apparent before an operation is required. The problem becomes apparent to athletes and their coaches/physiotherapists when the catch of pain upon release affects their performance and when symptoms encroach into fielding and even daily activities including their sleep.

In general, the earlier this is picked up, the quicker the recovery and the less likely it is that recurrent episodes will affect their career.

There are three main areas to work on:

1. Range of motion: By changing the arc of rotation, the GIRD is created, which is associated with internal impingement and a reduced "braking distance". However two simple stretching exercises can improve this range, reducing the rate of injury by up to $38 \%$ (in tennis players) [29].

One thing to note is that static stretching alone may not be enough and actually might be counterproductive before a match. The recommendations are that some basic cardio warm ups followed by dynamic stretching and sports specific exercises are best [30].

2. Strength and conditioning: It's not just about pushing weights. It's about developing a forceful balanced rapid bowling action with endurance and control. To my mind, the core is the keystone. The pelvis/core contributes to $54 \%$ of shoulder strength so the scientific fact is that a strong core means strong shoulders, and therefore less prone to injury. Sports specific drills are the key. In this instance, the work has just begun with weights and resistance bands for the cuff. Progress from here should involve perhaps Persian clubs (low weight, especially good for batsmen) and combined core/upper body exercises e.g. swiss ball press ups, superman's and swissball jackknife exercises.

What more do we need from our strength training? We need to develop our controlled strength but also the ability to generate power, or plyometrics. The term plyometrics was first coined by the famous track and field coach Fred Wilt in the 1970's in the US, but followed on from the "shock training" Eastern European coach of the 60's, Yuri Verkhoshansky, whose high intensity techniques was being pioneered in weightlifting, gymnastics and athletics. In overhead throwing we can split plyometrics into core training drills e.g. vertical and combination box jumps and sports specific drill eg. soft weight throwing and catching drills, onto medicine ball workouts. One thing 
to note is that the science tells us that there is little improvement by using weights more twice as heavy than the object you swing/throw in these drills. For instance a bowler should train with a weight no more than twice the weight of a cricket ball, but a shot-putter must use a much heavier weighted ball [31].

3. Balance is just as important as any form of power or strength: When you bowl or throw, the only way you can hit the ball forcefully, accurately and reliably is if your body underneath is stable and that stability starts from the feet. Every assessment starts with ankle stability (four point hops, wobble board and clinical examination). This follows all the way through the knees and hips and up through the spine to the shoulder girdle. Proprioceptive training has been shown to improve shoulder and core strength and therefore performance.

Some throwing arm injuries may fail to respond to non-surgical intervention. One such injury is a SLAP tear, which involves injury to the superior labrum and biceps anchor at the glenoid attachment. Snyder et al subdivided SLAP tears into 4 main types [32]. The type of lesion a patient has determines the operative management required. Overhead athletes most commonly present with Type II SLAP tears in which the superior labrum is completely torn off the glenoid. These are treated arthroscopically with partial debridement of the loose or frayed edges of the labrum to optimise it for re-attachment to the glenoid. The re-attachment itself is done by suturing the biceps-labral anchor back to the glenoid bone so that the labrum is able to heal back in the correct place.

Another common injury in overhead athletes which can require surgical treatment is a PASTA lesion. This is a partial tear of the supraspinatus tendon of the rotator cuff that does not extend to the full thickness of the rotator cuff. If non-operative rehabilitation has not been effective the tear is assessed for the percentage thickness of the rotator cuff tendon that is torn. If more than half the thickness is affected the tear undergoes surgical debridement. If more than $50 \%$ is affected it is treated similarly to a full thickness rotator cuff tear. This typically involves arthroscopic debridement and repair of the torn tendon by reattaching it to the bone using suture anchors. Occasionally it can also be repaired using an open procedure.

\section{Conclusion}

Overhead throwing athletes are trained to stretch the limits of the range of movement in their shoulder and load the muscles beyond their normal capacity. Additionally a lot of professional athletes are selected for their hypermobility. This training therefore can lead to a number of shoulder injuries, namely caused by the repetitive microtrauma to the muscle fibres, which can hinder both athletic performances but also everyday activities. In most cases the symptoms of these injuries present early on and can be identified and treated promptly with rehabilitation exercises but some conditions such as SLAP lesions and rotator cuff tears may require surgery.

\section{References}

1. Terry GC, Chopp TM (2000) Functional anatomy of the shoulder. J Athl Train 35: 248-255.

2. Kibler WB (1998) The role of the scapula in athletic shoulder function. Am J Sports Med 26: 325-337.

3. Kibler WB, Kuhn JE, Wilk K, Sciascia A, Moore S, et al. (2013) The disabled throwing shoulder: spectrum of pathology-10-year update. Arthroscopy 29: 141-161.
4. Ellenbecker TS, Roetert EP, Piorkowski PA, Schulz DA (1996) Glenohumeral joint internal and external rotation range of motion in elite junior tennis players. J Orthop Sports Phys Ther 24: 336-341.

5. Downar JM, Sauers EL (2005) Clinical Measures of Shoulder Mobility in the Professional Baseball Player. J Athl Train 40: 23-29.

6. Beach ML, Whitney SL, Dickoff-Hoffman S (1992) Relationship of shoulder flexibility, strength, and endurance to shoulder pain in competitive swimmers. J Orthop Sports Phys Ther 16: 262-268.

7. Altchek DW, Hobbs WR (2001) Evaluation and management of shoulder instability in the elite overhead thrower. Orthop Clin North Am 32: 423-430, viii.

8. Jobe FW, Kvitne RS, Giangarra CE (1989) Shoulder pain in the overhand or throwing athlete. The relationship of anterior instability and rotator cuff impingement. Orthop Rev 18: 963-975.

9. Jobe CM (1995) Posterior superior glenoid impingement: expanded spectrum. Arthroscopy 11: 530-536.

10. Walch G, Liotard JP, Boileau P, Noël E (1991) [Postero-superior glenoid impingement. Another shoulder impingement]. Rev Chir Orthop Reparatrice Appar Mot 77: 571-574.

11. Jobe CM (1997) Superior glenoid impingement. Orthop Clin North Am 28: 137-143.

12. Paley KJ, Jobe FW, Pink MM, Kvitne RS, ElAttrache NS (2000) Arthroscopic findings in the overhand throwing athlete: evidence for posterior internal impingement of the rotator cuff. Arthroscopy 16: 35-40.

13. Fortenbaugh D, Fleisig GS, Andrews JR (1993) Biomechanics of pitching with emphasis upon shoulder kinematics. J Orthop Sports Phys Ther 18: 402-408.

14. Stodden DF, Fleisig GS, McLean SP, Andrews JR (2005) Relationship of biomechanical factors to baseball pitching velocity: within pitcher variation. J Appl Biomech 21: 44-56.

15. Meister K (2000) Injuries to the shoulder in the throwing athlete. Part one: Biomechanics/pathophysiology/classification of injury. Am J Sports Med 28: 265-275.

16. Gowan ID, Jobe FW, Tibone JE, Perry J, Moynes DR (1987) A comparative electromyographic analysis of the shoulder during pitching. Professional versus amateur pitchers. Am J Sports Med 15: 586-590.

17. Jobe FW, Moynes DR, Tibone JE, Perry J (1984) An EMG analysis of the shoulder in pitching. A second report. Am J Sports Med 12: 218-220.

18. Kelly BT, Backus SI, Warren RF, Williams RJ (2002) Electromyographic analysis and phase definition of the overhead football throw. Am J Sports Med 30: 837-844.

19. Pappas AM, Zawacki RM, Sullivan TJ (1985) Biomechanics of baseball pitching. A preliminary report. Am J Sports Med 13: 216-222.

20. Hore J, Watts S, Tweed D (1996) Errors in the control of joint rotations associated with inaccuracies in overarm throws. J Neurophysiol 75: 1013-1025.

21. Sabick MB, Kim YK, Torry MR, Keirns MA, Hawkins RJ (2005) Biomechanics of the shoulder in youth baseball pitchers: implications for the development of proximal humeral epiphysiolysis and humeral retrotorsion. Am J Sports Med 33: 1716-1722.

22. Werner SL, Gill TJ, Murray TA, Cook TD, Hawkins RJ (2001) Relationships between throwing mechanics and shoulder distraction in professional baseball pitchers. Am J Sports Med 29: 354-358.

23. Reeves B (1968) Experiments on the tensile strength of the anterior capsular structures of the shoulder in man. J Bone Joint Surg Br 50: 858-865.

24. Toyoshima S, Hosikawa T, Miyashita M, Oguri T (1974) The contribution of body parts to throwing performance. In: Nelson RC, Morehouse CA, editors. International series on sports sciences 1, biomechanics IV. Baltimore: University Park Press 169-174.

25. David G, Magarey ME, Jones MA, Dvir Z, Türker KS, et al. (2000) EMG and strength correlates of selected shoulder muscles during rotations of the glenohumeral joint. Clin Biomech (Bristol, Avon) 15: 95-102. 
26. Kibler WB (1998) The relationship of glenohumeral internal rotation deficit to shoulder and elbow injuries in tennis players: a prospective evaluation of posterior capsular stretching. Annual closed meeting of the American Shoulder and Elbow Surgeons, Oct 3, New York, USA. Book of Abstract: 21.

27. Simic L, Sarabon N, Markovic G (2013) Does pre-exercise static stretching inhibit maximal muscular performance? A meta-analytical review. Scand J Med Sci Sports 23: 131-148.

28. Ratamess N (2011) ACSM's Foundations of Strength Training and Conditioning (American College of Sports Med). Lippincott Williams \& Wilkins.
29. Snyder SJ, Karzel RP, Pizzo WD, Ferkel RD, Friedman MJ (2010) Arthroscopy classics. SLAP lesions of the shoulder. Arthroscopy 26: 1117.

30. Jazrawi LM, McCluskey GM 3rd, Andrews JR (2003) Superior labral anterior and posterior lesions and internal impingement in the overhead athlete. Instr Course Lect 52: 43-63.

31. Wilk KE, Obma P, Simpson CD, Cain EL, Dugas JR, et al. (2009) Shoulder injuries in the overhead athlete. J Orthop Sports Phys Ther 39: 38-54.

32. Braun S, Kokmeyer D, Millett PJ (2009) Shoulder injuries in the throwing athlete. J Bone Joint Surg Am 91: 966-978. 